\title{
DMIP: A Method for Identifying Potentially Deliberate Metaphor in Language Use
}

\author{
W. Gudrun Reijnierse ${ }^{1,4}$ - Christian Burgers ${ }^{2} \cdot$ Tina Krennmayr $^{3} \cdot$ \\ Gerard J. Steen ${ }^{1}$
}

Received: 17 April 2017/Accepted: 25 September 2017/Published online: 25 October 2017

(C) The Author(s) 2017. This article is an open access publication

\begin{abstract}
This paper introduces the Deliberate Metaphor Identification Procedure (DMIP), a method for the systematic and reliable identification of potentially deliberate metaphor in language use. We take a semiotic approach to deliberate metaphor, and propose that, on a semiotic level, the distinction between potentially deliberate and non-deliberate metaphor hinges on the question whether the source domain functions as a distinct referent in the meaning of a metaphorical utterance. We present DMIP and illustrate the procedure in practice on the basis of the analysis of a series of real-world examples. We also report on inter-rater reliability testing. Finally, we discuss the implications of adopting DMIP as a tool for deliberatemetaphor analysis, and point out how this approach can contribute to the further development of Deliberate Metaphor Theory.
\end{abstract}

Keywords Deliberate metaphor · Deliberate Metaphor Theory · Identification procedure $\cdot$ Discourse $\cdot$ Corpus analysis

On April 19, 2016, Donald Trump won the Republican primary election in the state of New York. A few days later, The Guardian published an article about Trump's prospects for becoming the Republican candidate for President of the United States at the 2016 Presidential Elections. The headline of this article was: "The splinter is

W. Gudrun Reijnierse

g.reijnierse@let.ru.nl

1 Department of Dutch Studies, University of Amsterdam, Amsterdam, The Netherlands

2 Department of Communication Science, Vrije Universiteit Amsterdam, Amsterdam, The Netherlands

3 Department of Language, Literature, and Communication, Vrije Universiteit Amsterdam, Amsterdam, The Netherlands

4 Centre for Language Studies, Radboud University, Nijmegen, PO Box 9103, 6500 HD Nijmegen, The Netherlands 
coming: the Republican race is a real-life Game of Thrones plot" (Smith and Jacobs 2016). The first paragraphs of this article run as follows:

(1) The political battlefield is strewn with corpses. (...) 'Bom, bom, bom, bom. Now I'm left with two guys. Hardly two guys. Maybe you could say one. A half and a half.' If this were Game of Thrones, (...), Trump would be describing some gory dismemberment. But in America's Republican party equivalent, the businessman obsessed with gold has slashed his way through a field of 17 election candidates, as contemptuous of foes as Tywin Lannister (...). And although he put rivals to the sword in the New York primary this week, Trump appears to be looking over his shoulder, fearful of his own political demise.

(Smith and Jacobs 2016)

The authors of this article make ample use of metaphor-the figure of speech in which one thing (the target) is described in terms of another (the source; e.g., Lakoff and Johnson 1980). In (1), the target domain of POLITICs ${ }^{1}$ is described in terms of the source domain of WAR. Specifically, the race for the Republican presidential nomination is described in terms of a scene from the popular book series and television show Game of Thrones, with Trump as one of the main characters. The Republican race is described as a 'battlefield' that is covered with 'corpses' (candidates that withdrew from the Presidential race). Trump has been 'slashing through the field of candidates' (defeating them), and his victory in yet another US state is described as 'putting rivals to the sword' (defeating his Republican rivals in that specific primary election). Moreover, Donald Trump himself is linked to Tywin Lannister, the patriarch of one of the mightiest families in Game of Thrones, and the initiator of the infamous 'Red Wedding' in which Lannister's rival Robb Stark was betrayed and murdered.

This type of metaphor use can be compared to examples (2)-(4), which are taken from other newspaper articles that are also about the US primaries:

(2) Hillary Clinton attacks Bernie Sanders as New York primary looms

(Weaver 2016)

(3) The Battle for New York's Key Voting Blocs in the Primaries

(Fessenden and Almukhtar 2016)

(4) Ted Cruz takes anti-Trump campaign to Wyoming

(Associated Press 2016)

Like the Game of Thrones example in (1), examples (2)-(4) can be analysed as metaphorically describing the target domain of POLITICs in terms of the source domain of WAR. In example (2), Clinton criticising Sanders is described in terms of her using violence to metaphorically harm him ('attacks'). In (3), the situation in which candidates try to win the New York primary is described in terms of a fight ('battle'). And in (4), the things a politician does to try to win an election are

\footnotetext{
1 Following conventions in cognitive linguistics (e.g., Lakoff 1993), we use small capitals to indicate conceptual domains.
} 
described as a series of actions that an army performs to try to win a war ('campaign'). ${ }^{2}$

Despite the fact that examples (1) and (2)-(4) are similar in that they all make use of linguistic metaphors that describe the primary elections in war-related terms, a difference also exists between (1) on the one hand, and (2)-(4) on the other. In (1), the metaphors function as metaphors in communication between language users. They explicitly introduce a different perspective on the target domain of Trump's political success in the form of a (war) scene from Game of Thrones, and this is signalled in the text: 'If this were Game of Thrones, (...). But in America's Republican party equivalent...' 3 By contrast, in (2)-(4) there is no indication that the metaphors are used as metaphors, presenting an external perspective to the target domain of the utterance. In fact, the type of metaphors used in (2)-(4) may be so ingrained in language that they constitute the typical way in which people talk (and write) about politics; they are "just the way to say it" (Cameron 2003, p. 100).

Since the beginning of the 1980s, Conceptual Metaphor Theory (hereafter: CMT; Lakoff and Johnson 1980) has been the dominant theoretical framework in (cognitive) metaphor research (see Gibbs 2011c). One of the main claims of CMT is that our conceptual system is largely metaphorical, and that all metaphors in language are expressions of underlying metaphors in thought. Due to this cognitivelinguistic emphasis on the conceptual nature of metaphor (e.g., Kövecses 2002; Lakoff and Johnson 1980, 1999; Ortony 1993; Gibbs 1994), the distinct and variegated role of metaphor as a specific communicative device was given much less attention. Recently, researchers from various backgrounds have proposed to take the communicative function of metaphor into account, including in pragmatics (e.g., Carston 2010; Goddard 2004; Needham-Didsbury 2016), cognitive semiotics (e.g., Brandt and Brandt 2005; Bernárdez 2016), English as a Lingua Franca (e.g., MacArthur 2016; Nacey 2013), (discourse) dynamic approaches to metaphor (e.g., Cameron 1999, 2003; Müller 2008), corpus linguistics (e.g., Deignan 2005; Goatly 1997) and discourse analysis (e.g., Charteris-Black and Musolff 2003; Semino 2008; Steen 2008, 2011b, 2015). The proposals by Cameron (2003), Charteris-Black and Musolff (2003), and Steen (e.g., 2008, 2011b, 2015) are most closely related to the two-dimensional model of metaphor (Lakoff and Johnson 1980, 1999), in that they all take the dimensions of language and thought as a starting point. However, to incorporate the distinction between the type of metaphor use illustrated in (1) versus (2)-(4) into the model of metaphor, these authors propose an adjustment or extension of the cognitive-linguistic two-dimensional model of metaphor.

The proposal by Steen (e.g., 2008, 2011b, 2015), in particular, has lately attracted much attention among metaphor researchers (see, e.g., Charteris-Black 2012; Deignan 2011; Gibbs 2011a, b, 2015a, b; Müller 2011, 2016; Musolff 2016; Roncero et al. 2016; Xu et al. 2016). In this three-dimensional model, which has become known as Deliberate Metaphor Theory (hereafter: DMT), metaphor is not

\footnotetext{
${ }^{2}$ Please note that several other words in these examples can also be identified as related to metaphor, that do not necessarily fit the mapping between the domains of POLITICs and WAR: 'looms' in (2), 'in' in (3), and 'takes' in (4). For the sake of clarity, these words are ignored in the current analysis.

3 The title of the news item also refers to this comparison, when the presidential nomination is described as "a real-life Game of Thrones plot".
} 
only seen as the linguistic expression of an underlying metaphorical structure in thought, but also as a matter of communication between language users. In the third dimension, a distinction is made between metaphors that are used as metaphor (called 'deliberate metaphors'), and metaphors that do not have such a function (called 'non-deliberate metaphors').

Besides attention for the theoretical aspects related to the distinction between deliberate and non-deliberate metaphor, further valuable insights into the status of metaphor as a specific communicative device may be obtained by investigating the phenomenon from an empirical perspective. In fact, several studies have examined the occurrence of deliberate metaphor in various discourse settings (e.g., Beger 2011, 2016; Nacey 2013; Ng and Koller 2013; Pasma 2011; Perrez and Reuchamps 2014; see also Cameron 2003). However, a uniform operational definition and a tool for the identification of deliberate metaphor in discourse are not yet available (see Beger 2011; Ng and Koller 2013; Steen 2011b). ${ }^{4}$

In this paper, we aim to contribute to the further development of DMT by introducing an operational definition as well as a tool (DMIP) to systematically and reliably analyse potentially deliberate metaphor in natural language use. The establishment of an identification procedure makes it possible to move away from intuitive analyses of what analysts 'feel' counts as a potentially deliberate metaphor in discourse. A systematic, reliable, step-by-step procedure yields more objective analyses and results that can be replicated by other researchers.

In the next section, we first provide our operational definition of deliberate metaphor. Then, we present the method for deliberate metaphor identification (DMIP). We apply the procedure to a series of examples to illustrate how it works in practice. We also report the results of inter-rater reliability testing to show that DMIP can be reliably applied to identify potentially deliberate metaphor in natural language use. In the final section of this paper, the implications of adopting DMIP as a tool for deliberate metaphor analysis are discussed. We also point out how DMIP can contribute to the further development of DMT.

\section{Towards an Operational Definition of Deliberate Metaphor}

In DMT (e.g., Steen 2008, 2011b, c, 2015), metaphor is not only seen as a matter of conceptual structures (metaphor in thought) expressed in linguistic forms (metaphor in language), but also as a matter of communication between language users (metaphor in communication). In DMT, a distinction is consequently made between thoughts, the words that are used to express those thoughts, and the persons, things, actions, or events in the (text) world that the words refer to (referents). ${ }^{5}$ Such a three-dimensional model may be new to metaphor studies, but it is compatible with

\footnotetext{
4 Krennmayr's (2011) protocol for the identification of deliberate metaphor, IDeM, and Bogusławski's (1994) 'metalexical tag test' (see Goddard 2004) can be seen as exceptions. However, Krennmayr's protocol takes a top-down, rather than bottom-up approach. Bogusławski's approach is not an actual identification procedure, but rather a test for determining potential metalexical awareness.

5 In Goatly's (1997) approach to metaphor, reference is also a central notion in that referential meaning is "crucially important for reaching the Grounds of interpretation" (p. 110). However, Goatly does not
} 
longstanding models for utterance meaning in, for example, structural-functional theories of language (in particular Functional Discourse Grammar; e.g., Hengeveld 2004), as well as pragmatics (e.g., Relevance Theory; Wilson and Sperber 2002).

As pointed out above, at the dimension of metaphor in communication, DMT makes a distinction between deliberate and non-deliberate metaphor. When a metaphor is used deliberately, it provides an alien or alternative perspective on the topic of an utterance (Steen 2008, 2011b, 2015). This, in turn, implies that "the addressee has to move away their attention momentarily from the target domain of the utterance or even phrase to the source domain that is evoked by the metaphorrelated expression" (Steen 2015, p. 68). By contrast, a metaphor is called nondeliberate when it is not used as metaphor in communication between language users. From a communicative perspective, non-deliberate metaphors stay 'on topic', and the recipient does not have to attend to the source domain of the metaphorical utterance (Steen 2011b).

In DMT, the presence of attention to the source domain as a distinct domain of reference is the central feature of deliberate metaphor (Steen 2015). ${ }^{6}$ This can be investigated from two fundamentally different, but complementary perspectives: a semiotic and a behavioural perspective (Krennmayr 2011; Steen 2007; cf. Cameron 1999). Semiotic metaphor analyses describe the meaning of metaphorical utterances in a structural-functional way. Behavioural metaphor analyses are concerned with determining how such metaphorical utterances are processed by individual language users, in both production and reception, and/or what effects they have on reasoning. These two approaches each have their own research questions, methods of analysis, and outcomes. At the same time, the results of semiotic analyses may lead to concrete research hypotheses that psycholinguistic and psychological research can subsequently test, and the other way around (Gibbs 2015a).

In this paper, we take a semiotic approach to the identification of deliberate metaphor. This means that we investigate the multidimensional meaning of metaphorical utterances in text and transcripts of talk. Adopting a semiotic approach has several consequences for the way in which we operationalise deliberate metaphor (as would be the case when taking a behavioural approach). First of all, semiotic analyses do not make any claims about what in fact happens in specific individual language users' minds when they produce or process metaphors, nor about what happens in interaction between people using metaphor. This implies that a semiotic approach can only identify cases of potentially deliberate metaphor (Krennmayr 2011; Nacey 2013; Cameron 1999; Steen et al. 2010, for all metaphor). Whether those potentially deliberate metaphors are psychologically real for actual language users, and in which contexts, is a question that psycholinguistic and psychological research should subsequently test, using response-elicitation approaches such as experiments or interviews.

Footnote 5 continued

explicitly distinguish between three dimensions of metaphor in the sense of language, thought, and communication.

6 Please note that other researchers, most notably Müller (e.g., 2008, see also Müller and Tag 2010), and Carston (2010) have also mentioned attention as an important aspect of particular forms of metaphor use, for example in relation to foregrounding and activation of metaphoricity. 
Because we start from texts and transcripts of talk, we do not have direct access to the precise circumstances under which a metaphorical utterance is produced or received. We also do not have insight into the specific knowledge that discourse participants have (of the world, of word meanings) or share between them. To prevent the analyst's own intuitions from playing a role in the process of identifying potentially deliberate metaphors, it is important to use independent information about the different ways in which words can be used. Such information can be obtained from various resources, including large-scale corpora (e.g., Deignan 2005) and corpus-based dictionaries (e.g., Pragglejaz Group 2007; Steen et al. 2010; see also Semino et al. 2004). In this paper, we establish contemporary word meanings on the basis of a corpus-based dictionary. Following Steen et al. (2010; see also Krennmayr 2008), we use the online versions of the Macmillan English Dictionary and the Longman Dictionary of Contemporary English as sources. The entries and sense descriptions in these dictionaries are based on large corpora of contemporary texts. In this way, DMIP assumes (similar to MIPVU; Steen et al. 2010) an idealised contemporary language user, whose mental lexicon is represented in the dictionary. The use of corpus-based dictionaries as an independent source allows the systematic and reproducible analysis of natural language use. Any sense description for an entry in at least one of these dictionaries is considered a conventionalised meaning for that entry. Any meaning that cannot be found in these dictionaries is considered novel (see Semino 2008; Steen et al. 2010).

As a consequence of not making claims about processing (either during production or reception, or in interaction), a semiotic operational definition of deliberate metaphor should make explicit how attention to the source domain-the central feature of deliberate metaphor in DMT — can be observed in language use. As was argued above, the three dimensions of metaphor can be linked to the distinction between symbols, concepts, and referents. For a metaphor to count as potentially deliberate, it must not only be identified as a source-domain word at the linguistic level of utterance meaning and consequently as a source-domain concept at the conceptual level, but it also has to set up a source-domain referent in the state of affairs designated by the utterance (Steen 2017). Put otherwise, a metaphor is potentially deliberate when the source domain plays a role in the representation of the referential meaning of the utterance.

In (1), for instance, the noun 'corpses' is related to metaphor at the linguistic level of utterance meaning because it displays a contrast between the contextual meaning (related to politics) and a more basic meaning (related to violence or war). For the same reason, 'corpses' is metaphorical at the level of conceptual utterance meaning: the associated concept CORPSES comes from a different domain than the target domain of POLITICS. At the level of communication, 'corpses' can be connected to the explicit comparison between the Republican race and a war scene from Game of Thrones that is central to the news item. Additionally, only one sense description is present in the dictionary for "corpse': "the body of a dead person" (Macmillan), and this does not match the target domain of the primary elections. 'Corpses' consequently introduces a new perspective on the target domain of politics and thereby sets up a source domain referent in the state of affairs designated by the utterance. 'Corpses' is consequently identified as a potentially 
deliberate metaphor. Other words in (1) that can be identified as potentially deliberate metaphors include 'battlefield', 'slashed', and 'sword'. These words can also be connected to the explicit comparison between politics and war, and therefore set up source domain referents in the meaning of the utterance.

By contrast, a metaphor is non-deliberate when a word is metaphorical at the linguistic level and the associated concept is metaphorical at the conceptual level, but only a target domain referent (but no source domain referent) is present in the state of affairs designated by the utterance. This is the case in (2), where 'attacks' is metaphorical at the linguistic level because it displays a contrast between the target domain meaning of criticising, and a source domain meaning of using violence. The associated concept is metaphorical at the conceptual level of meaning because ATTACKS comes from a different domain than the target domain of POLITICS. However, contrary to 'corpses' and other linguistic metaphors in the Game of Thrones example in (1), the source domain meaning of 'attacks' does not play a role in the referential meaning of the utterance in (2). A conventionalised target domain meaning is available for the verb 'to attack' in the dictionary, and there is no indication that an external perspective on the target domain of criticising someone is introduced. This metaphor therefore counts as non-deliberate. ${ }^{7}$ Based on these considerations, we operationalise 'attention to the source domain' as: presence of a source domain referent in the state of affairs designated by the utterance (see Steen 2016).

A third and crucial aspect for our operational definition of deliberate metaphor is concerned with the way in which the presence of the source domain in the referential meaning of an utterance can be observed in language use. We argue that such presence of the source domain can be determined by looking for metaphor signals and other cotextual cues (see Steen 2015, 2016). In the literature, several suggestions have been put forward as to what such cues may look like (e.g., Krennmayr 2011; Nacey 2013; Steen 2016; see also Cameron and Deignan 2003; Goatly 1997; Semino 2008). These suggestions include lexical signals such as 'like' and 'as', the use of novel metaphor, and extended metaphor (multiple metaphor-related words expressing the same source-target domain mapping). These cues have been used to search for manifestations of potentially deliberate metaphor use in a top-down manner. However, the presence of a source domain referent in a metaphorical utterance can be suggested in many different ways, not just by lexical signals. To allow a thorough exploration of all possible manifestations of potentially deliberate metaphor in natural language use, our method therefore works bottom-up by analysing every metaphor-related word in a given text as well as top-down by analysing every metaphor-related word in the context of the genre event it partakes in.

The above observations show several important aspects that need to be taken into account for the operationalisation of deliberate metaphor for semiotic analysis: (1) the fact that only potentially deliberate metaphors can be identified; (2) the idea that the source domain has to be present in the referential meaning of a metaphorical

\footnotetext{
7 Please note that, if the verb 'to attack' would have been used in the Game of Thrones example, it would have been identified as potentially deliberate because it can be connected to the war-scenario that is presented in this example. This shows the importance of not equating conventional metaphor with nondeliberate metaphor, as well as the importance of taking a bottom-up approach when identifying potentially deliberate metaphors in discourse.
} 
utterance; and (3) the idea that the presence of such source domain referents can be traced by looking for cues. Based on these aspects, we operationalise deliberate metaphor as follows:

A metaphor is potentially deliberate when the source domain of the metaphor is part of the referential meaning of the utterance in which it is used.

\section{DMIP: A Method for Identifying Potentially Deliberate Metaphor in Language Use}

In this section, we introduce a step-by-step method for the identification of potentially deliberate metaphor in language use. A schematic overview of DMIP is presented in Fig. 1.

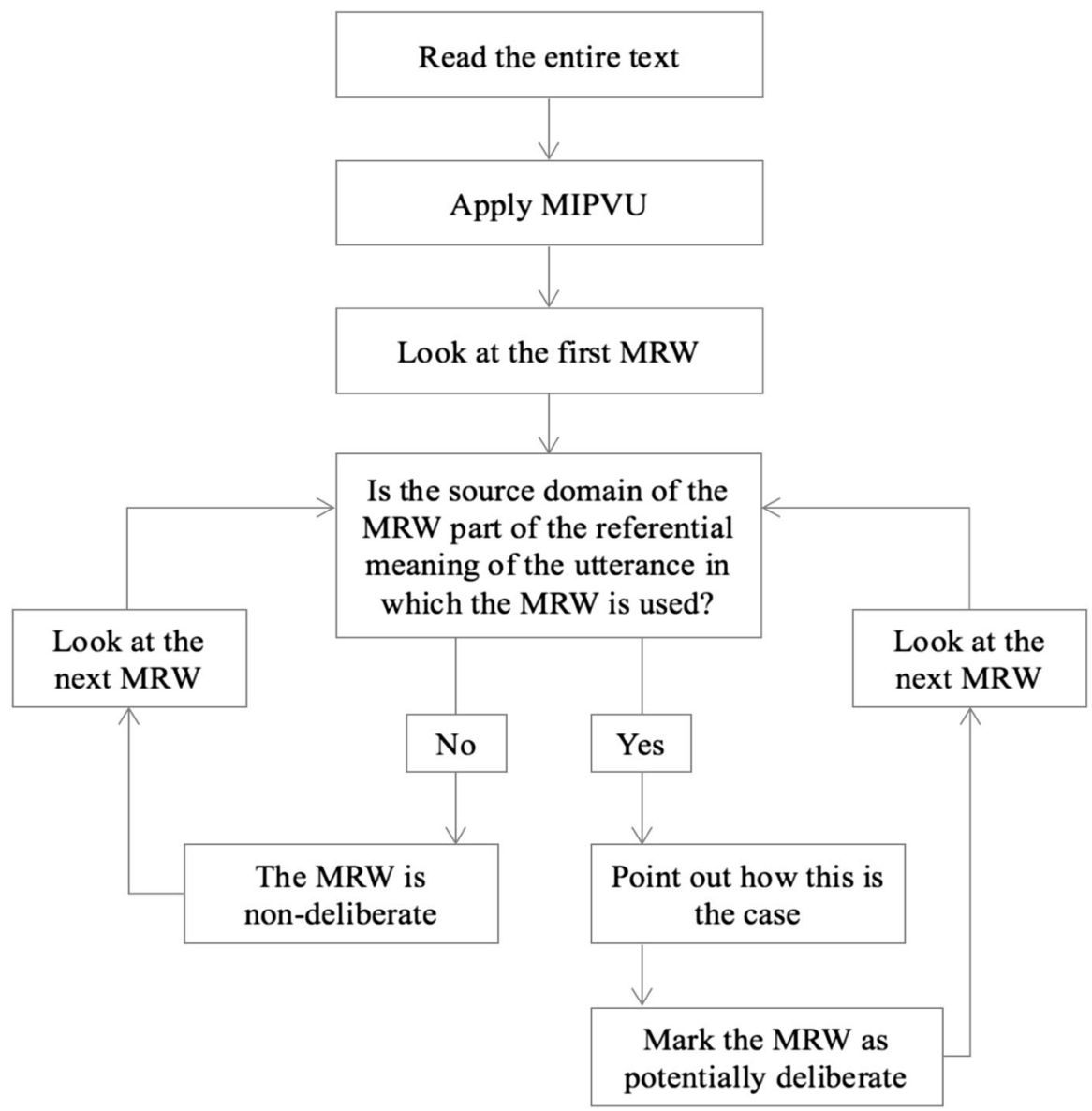

Fig. 1 The potentially deliberate metaphor identification procedure (DMIP) coding scheme 
1. Read the entire text to get a general idea of what the text is about.

2. Apply the Metaphor Identification Procedure Vrije Universiteit (MIPVU) to find all metaphorical lexical units (metaphor-related words, or MRWs; see Steen et al. 2010, for detailed instructions). ${ }^{8}$

3. Look at the first MRW.

4. Determine whether the source domain of the MRW is part of the referential meaning of the utterance in which the MRW is used.

a. If 'yes', mark the MRW as potentially deliberate and proceed to step 5 .

b. If 'no', mark the MRW as non-deliberate and proceed to step 6 .

c. In case of doubt, mark the MRW as potentially deliberate, and add the code WIDLII (When In Doubt Leave It In; see Steen et al. 2010). Then, proceed to step 5 .

5. If the MRW is coded as potentially deliberate in step 4, describe how the source domain of the MRW is part of the referential meaning of the utterance.

6. Look at the next MRW.

\section{Applying DMIP: Sample Analyses}

To illustrate how DMIP works in practice, we apply the procedure to a series of selected examples that contain various manifestations of potentially deliberate metaphor. All examples come from the VU Amsterdam Metaphor Corpus (hereafter: VUAMC). ${ }^{9}$ The VUAMC is a corpus of almost 190,000 lexical units, sampled from the British National Corpus. All lexical units in the VUAMC are annotated for metaphor by means of MIPVU (Steen et al. 2010), a reliable tool for the identification of linguistic metaphor in discourse. Please note that all lexical units that are identified as related to metaphor by MIPVU are followed by a superscript 'MRW' tag in the following analyses.

Example (5) comes from a newspaper article in which a journalist argues why a power station in London should be put on the English Heritage list, rather than being demolished. The author first describes a view over London:

(5) [From] the top of the dome of St Paul's Cathedral the view is no longer dominated $^{\mathrm{MRW}}$ by City church steeples but by an intrusive cacophony ${ }^{\mathrm{MRW}}$ of drab, characterless Sixties boxes.

(VUAMC-A4D-02)

Example (5) contains two lexical units that are identified as MRW by MIPVU: the verb 'dominated' and the noun 'cacophony'. First, the noun 'cacophony' is related to metaphor at the linguistic level of utterance meaning. Its contextual meaning is related to buildings, while its more basic meaning is related to the domain of sounds. 'Cacophony' is metaphorical at the conceptual level of utterance meaning

\footnotetext{
${ }^{8}$ Steen et al. (2010) use the term 'lexical unit' instead of 'word' because some units of analysis, such as multiword expressions, compounds, or phrasal verbs, consist of more than one word. In general, however, words and lexical units are the same (see Steen et al. 2010, pp. 26-32, for details).

9 The corpus is available online via http://ota.ahds.ac.uk/headers/2541.xml (Oxford Text Archive).
} 
for the same reason: the associated concept CACOPHONY comes from a different domain than the target domain of BUILDINGS.

The key question for determining whether the MRW 'cacophony' is potentially deliberate at the level of communication is whether the source domain of sound is part of the referential meaning of the utterance. In the case of 'cacophony', only one sense description is present in the dictionary: "an unpleasant mixture of loud sounds" (Macmillan). This sense description does not capture the 'buildings' target domain meaning of the noun, suggesting that no conventionalised target domain meaning is available. As a result, the metaphor can be taken to introduce a new perspective on the target domain, and the source domain is needed as a distinct referent in the state of affairs designated by the utterance. This makes 'cacophony' a potentially deliberate metaphor. The referential meaning for the second part of the utterance can consequently be spelled out as: “...the view is no longer dominated $^{\mathrm{MRW}}$ by City church steeples but by an intrusive mixture of buildings that is similar to an unpleasant mixture of loud sounds."

Example (5) also contains a second MRW: the verb 'dominated'. This verb displays a contrast between its contextual meaning related to buildings, and a human-oriented, historically older, basic meaning of powerful people controlling a situation. ${ }^{10}$ These two sense descriptions can be compared, making 'dominated' metaphorical at the linguistic level of utterance meaning. In a similar vein, 'dominated' is metaphorical at the conceptual level of utterance meaning because its associated concept comes from a different domain than the target domain of the utterance. In the case of 'dominate', a conventionalised metaphorical meaning is present in the dictionary that matches the target domain of the utterance: "if an object dominates a place, it is so big or high that it is easy to notice" (Macmillan sense description 4; hereafter: MM4, etc.). There is no cue in the utterance that suggests that the source domain of powerful people controlling a situation plays a role in the referential meaning of the utterance. A complete and coherent referential meaning of the utterance consequently consists of a target domain state of affairs only. The referential meaning of the utterance can be spelled out as: "From the top of the dome of St Paul's Cathedral, City church steeples are no longer easy to notice". This makes 'dominated' a non-deliberate metaphor.

The next example, (6), comes from a non-specialist book about palaeontology. It contains one lexical unit that is identified as MRW by MIPVU. In addition, MIPVU identifies the preposition 'like' as a signal of metaphor, or MFlag (indicated by a superscript 'MFlag' tag). In the extract, the author of the book describes a Cystosoma (a kind of shrimp), which has:

(6) enormously expanded eyes, looking like MFlag $_{\text {headlamps }}^{\text {MRW }}$

(VUAMC-AMM-02)

\footnotetext{
${ }^{10}$ In some cases, more than one sense description can be considered a candidate for the basic meaning, for instance because one description is more concrete, while another description is related to bodily action (see the criteria for more basic meanings in Pragglejaz Group 2007). In such cases, history may be taken into account as a 'tiebreaker' (see Krennmayr 2008). Because the 'control' sense (Macmillan sense description 1) is historically older (see the Oxford English Dictionary), this sense is taken as the basic, source domain meaning of the verb 'to dominate'.
} 
The noun 'headlamps' is identified as a metaphor-related word at the level of language, because it comes from a different domain than the target domain of animals, namely that of vehicles. The noun is also metaphorical at the conceptual level of utterance meaning, because the associated concept HEADLAMPS comes from a different domain than the target domain of the utterance.

To determine whether 'headlamps' counts as a case of potentially deliberate metaphor, we examine whether the example contains one or more cues suggesting that the source domain plays a role in the referential meaning of the utterance. In the case of 'headlamps', two cues can be found that this is indeed the case. First, in MIPVU terminology, 'headlamps' is a direct metaphor (Steen et al. 2010). This means that the lexical unit does not display a difference between a contextual and a more basic meaning - as is the case for indirect metaphor (see the metaphors discussed in examples (1)-(5); Steen et al. 2010). As a linguistic expression, a direct metaphor is not used metaphorically itself. That is, the contextual meaning of the noun 'headlamp' in (6) is 'headlamp', "one of the two lights on the front of a vehicle, used for driving at night" (Macmillan). ${ }^{11}$ However, 'headlamp' does express a cross-domain mapping in the form of a comparison (the eyes look like headlamps). This means that an external perspective is introduced into the discourse that directly refers to an autonomous source domain referent. Consequently, the source domain is present as a referent in the state of affairs designated by the utterance. Additional support for this view is provided by the preposition 'like', which explicitly signals that the eyes of an animal are compared to the lights at the front of a vehicle. The lexical unit 'headlamps' is consequently identified as a potentially deliberate metaphor. The referential meaning of (6) can therefore be spelled out as: "the cystosoma has enormously expanded eyes that look like the two lights on the front of a vehicle".

The next example, (7), comes from a newspaper article about the possible revival of the western on television. After pointing out that the series The Young Riders occupied the 51st place in the weekly audience rating of TV series, the author concludes:

(7) It is premature ${ }^{\mathrm{MRW}}$, then, to say that the western has galloped gRW $^{\mathrm{MRW}}$ back $^{\text {MRW }}$ to ${ }^{\text {MRW }}$ centre ${ }^{\text {MRW }}$ screen.

(VUAMC-A2D-05)

This example contains five lexical units that are identified as MRW by MIPVU: 'premature', 'galloped', 'back', 'to', and 'centre'. In the remainder of this analysis, the focus will be on the verb ('galloped'), the adverb ('back'), and the preposition ('to'). These three lexical units are identified as related to metaphor at the dimension of language, because they display a contrast between the contextual and a more basic meaning that can be related via comparison. For 'galloped', a sense description is available in the dictionary that captures the contextual meaning of the verb: "to move, pass, or develop very quickly" (MM2; emphasis added). This sense description contrasts with a more basic meaning of the verb: "if a horse gallops, it

\footnotetext{
11 Please note that both Macmillan and Longman define 'headlamp' as "a headlight", which is uninformative. Therefore, the sense description for 'headlight' is used.
} 
runs at its fastest speed" (MM1). At the same time, the revival of the western can be compared to the fast movement of a horse, making this a conventional metaphor. At first sight, there may not seem to be any cues in the utterance that point toward the presence of a source domain referent in the referential meaning of the utterance. In fact, the target domain sense for 'to gallop' ("to move, pass, or develop very quickly") is conventionalised, available, and it captures the referential meaning of the utterance. Consequently, the verb could at first glance be identified as a nondeliberate metaphor, in which case the referential meaning of the utterance could be spelled out as "It is [too soon], then, to say that the western has quickly developed back $^{\text {MRW }}$ to ${ }^{\text {MRW }}$ centre $^{\text {MRW }}$ screen".

Yet, as an analyst applying DMIP, we know that the newspaper article is about westerns (step 1 of the procedure). Given this information, it appears that the source domain meaning of this metaphorical lexical unit matches the overall topic of the text. That is, one of the key features of a western is that it includes horses (e.g., for cowboys to ride). In this example, lexis from the semantic field of the overall topic of the text is thus used in a figurative way (Herrera Soler et al. 2006). This is known as topic-triggered metaphor (Koller 2003) or context-induced metaphorical creativity (Kövecses 2009, 2010, 2015). Both the non-metaphorical (source domain) meaning and the metaphorical (target domain) meaning are relevant in the complex referential structure of this example, resulting in some kind of wordplay. Consequently, a full representation of the referential meaning of the utterance can only be established when this ambiguity is taken into account. The source domain referent is thus part of the referential meaning of the utterance. As a result, 'galloped' counts as a case of potentially deliberate metaphor.

As a result of the analysis of 'galloped' as a potentially deliberate metaphor, both the adverb 'back' and the preposition 'to' can also be identified as potentially deliberate. These two lexical units are both part of the same source domain 'scene' describing a horse running in a certain direction. The fact that (it is too soon to say that) the western is quickly becoming popular again on television is described in terms of a horse quickly running back to a place where it was before. The source domain meanings of both 'back' and 'to' express concrete movement (of the horse) into a particular direction, while the relevant target domain meanings describe the development of the western. As a result, both 'back' and 'to' are identified as potentially deliberate metaphors, too.

A final example, (8), to which we apply DMIP comes from a newspaper article describing an investment business that is going bankrupt:

(8) a small, investment business called Barlow Clowes had collapsed ${ }^{\mathrm{MRW}}$.

(VUAMC-AA3-08)

The verb 'collapsed' is identified as a MRW by MIPVU. This verb displays a contrast between its contextual meaning - concerned with a failing business - and a more basic (concrete and historically older) source domain meaning: "if a building or other structure collapses, it suddenly falls down" (MM1). ${ }^{12}$ 'Collapsed' is also

\footnotetext{
12 Macmillan contains a second sense description that can serve as a basic meaning, which is humanoriented: "to suddenly fall down and become very ill or unconscious" (MM2). Similar to the analysis of
} 
related to metaphor at the dimension of thought: the associated concept COLLAPSED comes from a different domain than the target domain of the utterance.

To determine whether the MRW 'collapsed' counts as a case of potentially deliberate metaphor, we examine whether there are cues suggesting that the source domain of buildings plays a role in the referential meaning of the utterance. In (8), no such cues are present. For the verb 'collapsed', a conventionalised metaphorical meaning is available in the dictionary that matches the target domain meaning of the utterance: "to suddenly fail or stop existing" (MM3). On the basis of this target domain meaning, a complete and coherent referential meaning for this example can be constructed, in which the source domain does not play a role. In contrast to the previous three examples, DMIP consequently identifies the MRW 'collapsed' as non-deliberate. The referential meaning of the utterance can be spelled out as follows: "a small, investment business called Barlow Clowes had suddenly stopped existing”.

\section{Assessing the Reliability of DMIP}

It is vital to report inter-rater reliability scores to show whether the application of a newly introduced identification procedure leads to sufficient agreement among analysts as to what counts as an instance of the phenomenon involved (and what not). One of the main reasons for creating DMIP is to move away from analysts' intuitions about what counts as a deliberate metaphor. Establishing a reliable method yields results that are independent of the analyst who performs the analysis. This makes it possible for other analysts to follow the decision process, and reproduce the results. And this, in turn, creates a uniform basis for discussion and comparison of results.

In the process of developing DMIP, a series of pilot studies were carried out in which three analysts (among whom the first author of this paper) applied the method to a series of sample sentences from the VUAMC. These pilots were used to improve DMIP, and each round led to minor adjustments to the method. To then examine whether the version of DMIP as it is presented in the current paper can indeed be considered a reliable method for the identification of potentially deliberate metaphor in discourse, we carried out two reliability tests. ${ }^{13}$ These tests were carried out by the first author of this paper, and one of the two other analysts who had been involved in the pilot phase of testing and improving the procedure.

The two coders independently applied DMIP to two sets of randomly selected metaphor-related words from the VUAMC. Results of the first reliability test show that the two coders agreed on the classification of these 129 MRWs as either potentially deliberate or non-deliberate in $93.8 \%$ of the cases. The associated Cohen's kappa for this test indicates "substantial agreement" $(\kappa=.70$; Landis and

\footnotetext{
Footnote 12 continued

'dominated' in (5), history was taken into account as a tiebreaker to determine the more basic meaning of the verb 'to collapse'.

13 The data and data-analytical procedures of the reliability test reported in this paper are publicly accessible on the Open Science Framework (OSF) at http://osf.io/9wh6r.
} 
Koch 1977, p. 165). Results of the second reliability test show that the two coders agreed on the classification of the second set of 130 MRWs as potentially deliberate or non-deliberate in $96.9 \%$ of the cases. Cohen's kappa for this test indicates "substantial agreement", as well ( $\kappa=.73$; Landis and Koch 1977, p. 165). These results indicate that the identification of potentially deliberate metaphor in language use can be carried out in a reliable way by means of the method for identifying potentially deliberate metaphor (DMIP), which was introduced in this paper.

\section{Conclusion and Discussion}

In this paper, we introduced DMIP, a reliable step-by-step method for the identification of potentially deliberate metaphor in language use. Our reasons for establishing such a method were twofold. Firstly, we aimed to advance the theory of deliberate metaphor (DMT; e.g., Steen 2008, 2011b, 2015) by approaching the notion of deliberateness from an empirical (more specifically: semiotic), rather than a theoretical angle. Secondly, we aimed to create a reliable tool for the semiotic analysis of deliberate metaphor in which analysts' intuitions do not play a role, and that can therefore yield reproducible results. In this respect, our method can be compared to other identification procedures, such as MIP (Pragglejaz Group 2007) and MIPVU (Steen et al. 2010) for linguistic metaphor identification; VIP for verbal irony identification (Burgers et al. 2011), and HIP for hyperbole identification (Burgers et al. 2016).

As a first step towards the development of DMIP, the theoretical definition of deliberate metaphor of requiring an addressee to move away their attention from a target domain to a source domain (Steen 2015) was translated into an operational definition. Our definition is as follows: "A metaphor is potentially deliberate when the source domain of the metaphor is part of the referential meaning of the utterance in which it is used". This operational definition was then used to establish DMIP. On the basis of a series of sample analyses, we have shown that DMIP allows for a broad variety of metaphors to be identified as potentially deliberate. At the same time, the results of the inter-rater reliability test showed that two coders can reliably apply the procedure.

We have introduced DMIP as a methodological tool to investigate the underlying semiotic structures of potentially deliberate metaphor. The procedure requires analysts to make a dichotomous choice between 'potentially deliberate' and 'nondeliberate' metaphor. Such a binary decision yields a coarse-grained picture of the role of metaphor as metaphor in communication between language users that is clearly a reduction of the complexity and wealth of actual language use. However, the binary perspective adopted by DMIP allows for quantitative results in the form of a general overview of the frequency of potentially deliberate (as compared to nondeliberate) metaphor in language use. It can also be used to investigate how frequent potentially deliberate metaphor is used - and how it is distributed-across a variety of registers and word classes, for instance along the same lines as Steen et al. (2010).

That is not to say, however, that all MRWs that are identified as potentially deliberate on the basis of DMIP fit into one homogenous group (and the same can be said for non-deliberate metaphors). On the contrary, a wide range of manifestations 
of metaphorical language use may be identified as potentially deliberate, based on specific cues in metaphorical utterances. In the analyses presented in this paper, we have shown that such cues can, for instance, consist of lexical signals ('like'), the use of direct metaphor, and wordplay. However, it is important to note that these examples by no means display the entire range of possible cues. Other features that could serve as cues of potentially deliberate metaphor include, for instance, the recontextualisation of metaphors from one (con)text to the next (Linell 1998; see Semino et al. 2013). An example of this is the "welcome to Holland" metaphor which, as Semino et al. (2013) describe, was first used in an essay to describe life with a special needs child, and which has been re-used, extended, adjusted and critiqued in various other texts and genres since then. Other cues of potentially deliberate metaphor can be found when applying the procedure to (recorded) spoken discourse, including paralinguistic features such as intonation and stress, as well as gestures (see Cienki 2016). This is why it is important to perform the identification of potentially deliberate metaphor in a bottom-up fashion, starting from the data rather than from a set list of features to look for. Further, detailed, analyses should investigate whether or how the two main categories of potentially deliberate and non-deliberate metaphor can be subdivided into more specific categories. The content provided by the analyst in step 5 of the procedure can be used as a starting point for such analysis. In this step, the analyst is asked to point out how the source domain of the MRW is part of the referential meaning of the utterance.

One of the main consequences of the semiotic approach to deliberate metaphor adopted in this paper is that DMIP does not investigate whether metaphor-related words are processed deliberately as metaphors by individual language users-either addressers or addressees - in communication. That is, a metaphor may be produced and received as a deliberate metaphor, but asymmetry may also occur, in particular when a metaphor is produced as a deliberate metaphor, but not be received as such, or the other way around (see Goatly 1997). Whether, when, and under which specific conditions these various ways of processing happen is a question that further psycholinguistic analyses have to investigate. Such behavioural studies may also shed light on the question whether the metaphors that DMIP identifies as potentially deliberate are indeed processed by means of cross-domain mappings. This is one of the main predictions of DMT (Steen 2008, 2011b), and the application of DMIP can provide the data to serve as a starting point for psycholinguistic and/or psychological experiments testing this prediction.

Behavioural studies may also investigate to what extent further factors are relevant in deliberate metaphor processing, such as register, communicative setting, salience, aptness, individual language users' linguistic/world knowledge, emotions, embodied simulation, visual imagery, and so on. All of these aspects may play a role in the production, reception, and effects of deliberate metaphor. They should be taken into account if we want to arrive at a fuller understanding of the role and function of metaphor in communication between language users. However, these are all aspects that cannot be determined on the basis of texts and transcripts of talk (alone); consequently, they do not play a role in the identification procedure proposed in this paper.

In DMT, however, predictions about the way in which deliberate versus nondeliberate metaphor is processed are established in connection with theories of text 
comprehension in discourse psychology (e.g., Van Dijk and Kintsch 1983; McNamara and Magliano 2009). The level of referential utterance meaning that plays an important role in DMIP can be connected to the situation model that readers or listeners construct during discourse comprehension, and which is concerned with "the cognitive representation of the events, actions, persons, and in general the situation, a text is about" (Van Dijk and Kintsch 1983, p. 11). ${ }^{14}$ When a metaphor is deliberate, the prediction is that both the source domain and the target domain meaning of the metaphor are activated in people's situation model of the discourse (Steen 2017). By contrast, when a metaphor is non-deliberate, the prediction is that only the target domain meaning of the metaphor is activated in the situation model (Steen 2017). In making predictions about the activation of metaphorical meaning in some but not all metaphorical expressions, DMT can be connected with other recent theoretical proposals about metaphor processing, such as Bowdle and Gentner's (2005) 'Career of Metaphor theory', Carston's (2010; see also Needham-Didsbury 2016) account of two routes of metaphor processing, Goatly's (1997; see also Deignan 2005) model of dead, buried, sleeping, tired, and active metaphors, and Müller's (2008) dynamic view of metaphor (see Müller 2016).

Ultimately, the combination of semiotic and behavioural approaches to (potentially) deliberate metaphor will lead to a fuller understanding of the role of metaphor in communication, as well as to a fuller developed theory of deliberate metaphor. By introducing DMIP, in which deliberate metaphor is operationalised from a semiotic perspective, we hope to have contributed to this development in the current paper.

Acknowledgements The contribution of W. Gudrun Reijnierse was supported by Grant No. 322-89-006, awarded by the Netherlands Organization for Scientific Research (NWO), www.nwo.nl. The research reported in this paper is part of Reijnierse's doctoral dissertation, supervised by the second, third, and fourth author. This research was carried out within the Metaphor Lab Amsterdam, a joint venture of the Network Institute (Vrije Universiteit Amsterdam) and the Amsterdam Center for Language and Communication (ACLC; University of Amsterdam), www.metaphorlab.amsterdam. Reijnierse is currently at the Centre for Language Studies at Radboud University Nijmegen, The Netherlands. The authors would like to thank Kiki Y. Renardel de Lavalette for her assistance with reliability coding.

Open Access This article is distributed under the terms of the Creative Commons Attribution 4.0 International License (http://creativecommons.org/licenses/by/4.0/), which permits unrestricted use, distribution, and reproduction in any medium, provided you give appropriate credit to the original author(s) and the source, provide a link to the Creative Commons license, and indicate if changes were made.

\section{References}

Beger, A. (2011). Deliberate metaphors? An exploration of the choice and functions of metaphors in USAmerican College lectures. Metaphorik.de, 20, 39-60.

\footnotetext{
14 Likewise, the levels of linguistic and conceptual utterance meaning can be connected to Van Dijk and Kintsch's (1983) surface text and text base, respectively (see also Steen 2011a).
} 
Beger, A. (2016). Different functions of (deliberate) metaphor in teaching scientific concepts. Metaphorik.de, 26, 57-84.

Bernárdez, E. (2016). From butchers and surgeons to the linguistic method. On language and cognition as supraindividual phenomena. In M. Romano \& M. D. Porto (Eds.), Exploring discourse strategies in social and cognitive interaction: Multimodal and cross-linguistic perspectives (pp. 21-38). Amsterdam: John Benjamins.

Bogusławski, A. (1994). Non-literal interpretation, metaphor, analogical proportion. In A. Bogusławski (Ed.), Word matters (pp. 137-155). Warsaw: Veda.

Bowdle, B. F., \& Gentner, D. (2005). The career of metaphor. Psychological Review, 112(1), $193-216$. doi:10.1037/0033-295X.112.1.193.

Brandt, L., \& Brandt, P. A. (2005). Making sense of a blend. A cognitive-semiotic approach to metaphor. Annual Review of Cognitive Linguistics, 3, 216-249. doi:10.1075/arcl.3.12bra.

Burgers, C., Brugman, B. C., Renardel de Lavalette, K. Y., \& Steen, G. J. (2016). HIP: A method for linguistic hyperbole identification in discourse. Metaphor and Symbol, 31(3), 163-178. doi:10.1080/ 10926488.2016.1187041.

Burgers, C., van Mulken, M., \& Schellens, P. J. (2011). Finding irony: An introduction of the Verbal Irony Procedure (VIP). Metaphor and Symbol, 26(3), 186-205. doi:10.1080/10926488.2011.583194.

Cameron, L. (1999). Operationalising 'metaphor' for applied linguistic research. In L. Cameron \& G. Low (Eds.), Researching and applying metaphor (pp. 3-28). Cambridge: Cambridge University Press.

Cameron, L. (2003). Metaphor in educational discourse. London/New York: Continuum.

Cameron, L., \& Deignan, A. (2003). Combining large and small corpora to investigate tuning devices around metaphor in spoken discourse. Metaphor and Symbol, 18(3), 149-160. doi:10.1207/ S15327868MS1803_02.

Carston, R. (2010). Metaphor: Ad hoc concepts, literal meaning and mental images. Proceedings of the Aristotelian Society, 110(3), 297-323. doi:10.1111/j.1467-9264.2010.00288.x.

Charteris-Black, J. (2012). Forensic deliberations on purposeful metaphor. Metaphor and the Social World, 2(1), 1-12. doi:10.1075/msw.2.1.01cha.

Charteris-Black, J., \& Musolff, A. (2003). 'Battered hero' or 'innocent victim'? A comparative study of metaphors for euro trading in British and German financial reporting. English for Specific Purposes, 22, 153-176. doi:10.1016/S0889-4906(02)00012-1.

Cienki, A. (2016). Speakers' (possible) metacommunicative awareness: a multimodal perspective, with special attention to metaphor. Paper presented at The premeditated path: Deliberate metaphor in ancient and modern texts conference, Berlin, Germany.

Deignan, A. (2005). Metaphor and corpus linguistics. Amsterdam: John Benjamins.

Deignan, A. (2011). Deliberateness is not unique to metaphor. A response to Gibbs. Metaphor and the Social World, 1(1), 57-60. doi:10.1075/msw.1.1.05dei.

Fessenden, F., \& Almukhtar, S. (2016). The battle for New York's key voting blocs in the Primaries. The New York Times. Retrieved from http://www.nytimes.com/interactive/2016/04/17/us/elections/newyork-primary-republican-democrat.html?_r=0.

Gibbs, R. W. (1994). The poetics of mind: Figurative thought, language, and understanding. Cambridge: Cambridge University Press.

Gibbs, R. W. (2011a). Advancing the debate on deliberate metaphor. Metaphor and the Social World, 1(1), 67-69. doi:10.1075/msw.1.1.07gib.

Gibbs, R. W. (2011b). Are deliberate metaphors really deliberate? A question of human consciousness and action. Metaphor and the Social World, 1(1), 26-52. doi:10.1075/msw.1.1.03gib.

Gibbs, R. W. (2011c). Evaluating conceptual metaphor theory. Discourse Processes, 48(8), 529-562. doi:10.1080/0163853X.2011.606103.

Gibbs, R. W. (2015a). Do pragmatic signals affect conventional metaphor understanding? A failed test of deliberate metaphor theory. Journal of Pragmatics, 90, 77-87. doi:10.1016/j.pragma.2015.05.021.

Gibbs, R. W. (2015b). Does deliberate metaphor theory have a future? Journal of Pragmatics, 90, 73-76. doi:10.1016/j.pragma.2015.03.016.

Goatly, A. (1997). The language of metaphors. London/New York: Routledge.

Goddard, C. (2004). The ethnopragmatics and semantics of 'active metaphors'. Journal of Pragmatics, 36, 1211-1230. doi:10.1016/j.pragma.2003.10.011.

Hengeveld, K. (2004). The architecture of a Functional Discourse Grammar. In J. L. Mackenzie \& M. Á. Gómez-González (Eds.), A new architecture for Functional Grammar (Functional Grammar Series 24) (pp. 1-21). Berlin: Mouton de Gruyter. 
Herrera Soler, H., White, M., Villacañas, B., \& Amengual, M. (2006). Figurative language in English and Spanish business press headlines and its effects on inter- and intra-cultural communication. Universität Duisburg-Essen. LAUD Paper No, 661, 1-27.

Macmillan English Dictionary Online. July, 2016. http://www.macmillandictionary.com/.

Koller, V. (2003). Metaphor clusters in business media discourse: A social cognition approach. Dissertion, Vienna University. http://www.wuwien.ac.at/inst/english/koller_diss.pdf.

Kövecses, Z. (2002). Metaphor: A practical introduction. Oxford: Oxford University Press.

Kövecses, Z. (2009). The effect of context on the use of metaphor in discourse. Ibérica, 17, 11-24.

Kövecses, Z. (2010). A new look at metaphorical creativity in cognitive linguistics. Cognitive Linguistics, 21(4), 663-697. doi:10.1515/COGL.2010.021.

Kövecses, Z. (2015). Where metaphors come from. Reconsidering context in metaphor. Oxford: Oxford University Press.

Krennmayr, T. (2008). Using dictionaries in linguistic metaphor identification. In N.-L. Johannesson \& D. C. Minugh (Eds.), Selected papers from the 2006 and 2007 Stockholm Metaphor Festivals (pp. 97-115). Stockholm: Acta Universitatis Stockholmiensis.

Krennmayr, T. (2011). Metaphor in newspapers. LOT Dissertation Series, vol. 276, Utrecht.

Lakoff, G. (1993). The contemporary theory of metaphor. In A. Ortony (Ed.), Metaphor and thought (2nd ed., pp. 202-251). Cambridge: Cambridge University Press.

Lakoff, G., \& Johnson, M. (1980). Metaphors we live by. Chicago: University of Chicago Press.

Lakoff, G., \& Johnson, M. (1999). Philosophy in the flesh: The embodied mind and its challenge to western thought. New York: Basic Books.

Landis, J. R., \& Koch, G. G. (1977). The measurement of observer agreement for categorical data. Biometrics, 33(1), 159-174. doi:10.2307/2529310.

Linell, P. (1998). Discourse across boundaries: On recontextualizations and the blending of voices in professional discourse. Text, 18(2), 143-157. doi:10.1515/text.1.1998.18.2.143.

Longman Dictionary of Contemporary English Online. July, 2016. http://www.ldoceonline.com/.

MacArthur, F. (2016). Overt and covert uses of metaphor in the academic mentoring in English of Spanish undergraduate students at five European universities. Review of Cognitive Linguistics, 14(1), 23-50. doi:10.1075/rcl.14.1.02mac.

McNamara, D. S., \& Magliano, J. (2009). Toward a comprehensive model of comprehension. In B. Ross (Ed.), The psychology of learning and motivation (Vol. 51, pp. 297-384). Burlington, VT: Academic Press.

Müller, C. (2008). Metaphors dead and alive, sleeping and waking. Chicago/London: University of Chicago Press.

Müller, C. (2011). Are 'deliberate' metaphors really special? Deliberateness in the light of metaphor activation. Metaphor and the Social World, 1(1), 61-66. doi:10.1075/msw.1.1.06mul.

Müller, C. (2016). Why mixed metaphors make sense. In R. W. Gibbs (Ed.), Mixing metaphor (pp. 31-56). Amsterdam: John Benjamins.

Müller, C., \& Tag, S. (2010). The dynamics of metaphor: foregrounding and activating metaphoricity in conversational interaction. Cognitive Semiotics, 6, 85-120. doi:10.1515/cogsem.2010.6.spring2010. 85.

Musolff, A. (2016). Cross-cultural variation in deliberate metaphor interpretation. Metaphor and the Social World, 6(2), 205-224. doi:10.1075/msw.6.2.02mus.

Nacey, S. (2013). Metaphors in learner English. Amsterdam: John Benjamins.

Needham-Didsbury, I. (2016). Interpreting metaphor: perspectives from pragmatics and psychotherapy. Diss. University College London. http://www.cleanlanguage.co.uk/articles/attachments/Needhamidsbury_Application_of_Metaphors_in_Psychotherapy.pdf.

Ng, C. J. W., \& Koller, V. (2013). Deliberate conventional metaphor in images: The case of corporate branding discourse. Metaphor and Symbol, 28(3), 131-147. doi:10.1080/10926488.2013.797807.

Ortony, A. (Ed.). (1993). Metaphor and thought (2nd ed.). Cambridge: Cambridge University Press. Oxford English Dictionary Online. January, 2017. http://www.oed.com/.

Pasma, T. (2011). Metaphor and register variation. The personalization of Dutch news discourse. Oisterwijk: Box Press.

Perrez, J., \& Reuchamps, M. (2014). Deliberate metaphors in political discourse: The case of citizen discourse. Metaphorik.de, 25, 7-41.

Pragglejaz Group. (2007). MIP: A method for identifying metaphorically used words in discourse. Metaphor and Symbol, 22(1), 1-39. doi:10.1080/10926480709336752. 
Roncero, C., de Almeida, R. G., Martin, D. C., \& de Caro, M. (2016). Aptness predicts metaphor preference in the lab and on the internet. Metaphor and Symbol, 31(1), 31-46. doi:10.1080/ 10926488.2016.1116908.

Semino, E. (2008). Metaphor in discourse. Cambridge: Cambridge University Press.

Semino, E., Deignan, A., \& Littelmore, J. (2013). Metaphor, genre, and recontextualization. Metaphor and Symbol, 28(1), 41-59. doi:10.1080/10926488.2013.742842.

Semino, E., Heywood, J., \& Short, M. (2004). Methodological problems in the analysis of metaphors in a corpus of conversations about cancer. Journal of Pragmatics, 36, 1271-1294. doi:10.1016/j.pragma. 2003.10.013.

Smith, D., \& Jacobs, B. (2016). The splinter is coming: the Republican race is a real-life Game of Thrones plot. The Guardian. Retrieved from http://www.theguardian.com/us-news/2016/apr/23/us-electiontrump-cruz-republicans-game-of-thrones-plot.

Steen, G. J. (2007). Finding metaphor in grammar and usage: A methodological analysis of theory and research. Amsterdam: John Benjamins.

Steen, G. J. (2008). The paradox of metaphor: Why we need a three-dimensional model of metaphor. Metaphor and Symbol, 23(4), 213-241. doi:10.1080/10926480802426753.

Steen, G. J. (2011a). From three dimensions to five steps: The value of deliberate metaphor. Metaphorik.de, 21, 83-110.

Steen, G. J. (2011b). The contemporary theory of metaphor-Now new and improved! Review of Cognitive Linguistics, 9(1), 26-64. doi:10.1075/ml.9.1.03ste.

Steen, G. J. (2011c). What does 'really deliberate' really mean? More thoughts on metaphor and consciousness. Metaphor and the Social World, 1(1), 53-56. doi:10.1075/msw.1.1.04ste.

Steen, G. J. (2015). Developing, testing and interpreting deliberate metaphor theory. Journal of Pragmatics, 90, 67-72. doi:10.1016/j.pragma.2015.03.013.

Steen, G. J. (2016). Mixed metaphor is a question of deliberateness. In R. W. Gibbs (Ed.), Mixing metaphor (pp. 113-132). Amsterdam: John Benjamins.

Steen, G. J. (2017). Attention to metaphor: Where embodied cognition and social interaction can meet, but may not often do so. In B. Hampe (Ed.), Metaphor. Embodied cognition and discourse (pp. 279-296). Cambridge: Cambridge University Press.

Steen, G. J., Dorst, A. G., Herrmann, J. B., Kaal, A. A., Krennmayr, T., \& Pasma, T. (2010). A method for linguistic metaphor identification: From MIP to MIPVU. Amsterdam: John Benjamins.

Ted Cruz takes anti-Trump campaign to Wyoming. (2016). Associated Press. Retrieved from http:// elections.ap.org/content/ted-cruz-takes-anti-trump-campaign-wyoming.

Van Dijk, T. A., \& Kintsch, W. (1983). Strategies of discourse comprehension. New York: Academic Press.

Weaver, C. (2016). Hillary Clinton attacks Bernie Sanders as New York primary looms. Financial Times. Retrieved from http://www.ft.com/cms/s/0/9ffe8a46-02ba-11e6-99cb-83242733f755.html\#axzz4Ens 8BLZ5.

Wilson, D., \& Sperber, D. (2002). Relevance theory. UCL Working Papers in Linguistics, 14, $249-287$.

$\mathrm{Xu}, \mathrm{C}$., Zhang, C., \& Wu, Y. (2016). Enlarging the scope of metaphor studies. Intercultural Pragmatics, 13(3), 439-447. doi:10.1515/ip-2016-0018. 